\title{
Жанмуратов А.
}

Ғылыми жетекші: Сансызбай К.

\section{Теміржол желілерінде ТҚП ұлттық жүйесін енгізу жолымен поездар қозғалысының ақпараттық қауіпсіздігін қамтамасыз ету}

Андатпа. Бұл мақалада заманауи техникалық шешімдер негізінде пойыздар қозғалысын қауіпсіз және тиімді басқару үшін ұлттық KTCS жүйесін құру қажеттілігі талқыланады. Мақалада ұлттық KTCS жүйесінің негізгі компоненттері көрсетілген, осы жүйенің жұмыс принципі қарастырылған, TETRA стандартының сандық радио байланысы қамтамасыз етілген.

Кілт сөздер. KTCS, стандарт TETRA, rail transport, Direct Mode Operation, Trunked Mode Operation.

\section{About authors:}

Zhanmuratov Azat, student, Academy of Transport and Communications named after M.Tynyshpaev.

Sansyzbay K.M., senior-lector, Academy of Transport and Communications named after M.Tynyshpaev.

УДК 004.032.26, 620.3, 541.64

\author{
Аликулов А.Ж. ${ }^{1}$, Серікбай А.М. ${ }^{2}$, Молдахан И. ${ }^{3}$ \\ 1,2 Казахский национальный университет имени аль-Фараби \\ Алматы, Казахстан \\ ${ }^{3}$ Алматинский университет энергетики и связи им. Г. Даукеева \\ Алматы, Казахстан \\ Научный руководитель: Г.А. Мун
}

\section{ПРОБЛЕМЫ МАКРОСКОПИЧЕСКОЙ ЗАПИСИ ИНФОРМАЦИИ В НАНОРАЗМЕРНЫХ СТРУКТУРАХ}

\begin{abstract}
Аннотация. В работе показан подход с использованием нейронов, обладаюшим двумя входами, которые отвечают двум различным термодинамическим переменным. Отработаны макромолекулярные системы, которые действительно представляют собой аналог нейронной сети и которые позволяют записывать информачию на молекулярном уровне.

Ключевые слова: инфокоммуникационные технологии, нейронные сети, нанотехнологии, макромолекулярные системы.

В литературе, посвящённой инфокоммуникационным технологиям уже продолжительное время обсуждается так называемый закон Мура. Этот закон фактически представляет собой аппроксимацию данных, отражающих количество логических элементов, которые располагаются на отдельной микросхеме. Данная аппроксимация показывает, что в обозримой перспективе логические элементы должны стать сопоставимыми с размерами отдельных макромолекул. Это соображение говорит о том, что для того, чтобы инфокоммуникационные технологии развивались дальше в том же русле, в котором они развиваются сейчас, необходимо перейти к логическим элементам, имеющим не просто наноразмеры, но и размеры, сопоставимые с отдельными фрагментами макромолекул. Подчеркиваем ещё раз, что тенденция на уменьшение размеров отдельного логического элемента связана далеко не только с миниатюризацией компьютерной техники, но и с их вычислительными возмож-
\end{abstract}


ностями. Следовательно, создание программируемых молекулярных структур является более чем актуальной задачей.

В настоящее время в Казахстане бурно развивается соответствующее научное направление, которое было названо молекулярной информатикой. Данное научное направление учитывает принципиальное различие между подходами к созданию логических элементов на полупроводниках и логическими элементами, которые могли бы создаваться на основе макромолекул. Конкретно, речь идёт о том, что запись информации в наноразмерные системы должна осуществляться весьма специфическим образом.

Несколько упрощая, если к отдельному полупроводниковому элементу, на которых построен современный компьютер, можно направить сигнал по отдельному проводу или тому, что его заменяет, то применительно к наноразмерным системам такая возможность отсутствует, иными словами, необходимо записать информацию принципиально другим путем. Для этого молекулярная информатика отталкивается от нового принципа записи информации в наноразмерные системы при помощи изменения термодинамических переменных. Данный принцип является вполне работоспособным, так как было показано в работах [1] многие растворы полимеров в действительности представляют собой аналоги нейронной сети Хопфилда. Следовательно, для того, чтобы этот подход стал реализуем, нужно реализовать такую нейронную сеть на основе макромолекул, которая бы позволяла записывать информацию при условии, что на все входы нейронов подаётся один и тот же сигнал.

В данной работе показано, что этот подход является вполне реализуемым, если использовать нейроны, обладающие двумя входами. Здесь два входа каждого из нейронов отвечают двум различным термодинамическим переменным, в качестве которых может выступать, например, температура и ионная сила раствора. Оба эти параметра регулируются макроскопически, но тем не менее использование нейросетевых принципов позволяет записывать информацию в систему на молекулярном уровне. В порядке иллюстрации к реализуемости данного подхода можно отметить следующее. Типовая нейронная сеть, которая сейчас часто используется для различных приложений предполагает, что на входы всех нейронов первого слоя подаются различные сигналы. С некоторой долей условности можно сказать, что здесь идет речь об образе, который распределен в пространстве. Если же использовать подходы молекулярной информатики, то речь идет об образе, который распределён во времени. Кодировка той информации, которая записывается в систему на молекулярном уровне, осуществляется за счёт изменения во времени двух термодинамических переменных. В данной работе представлена модель, которая доказывает работоспособность этого подхода.

Отработаны также макромолекулярные системы, которые действительно представляют собой аналог нейронной сети и которые позволяют записывать информацию на молекулярном уровне. Эти макромолекулярные системы основываются на сравнительно новом классе продуктов химической реакции между полимерными макромолекулами, так называемыми гидрофильными интерполимерными ассоциатами. Этот продукт является промежуточным по отношению и к классическим интерполимерным комплексам, и по отношению к истинным раствором, и по отношению к полимерным гидрогелям. Гидрофильный интерполимерный ассоциат представляет собой сетку, существующую в динамическом режиме, связи, в которой то возникают, то разрушаются снова. Наиболее важным с точки зрения молекулярной информатики является то, что несмотря на нестабильность данного объекта, он позволяет хранить информацию именно за счёт нейросетевых свойств, она является распределенной. 


\section{ЛИТЕРАТУРА}

1. Сулейменов И.Э., Мун Г.А. Концепция развития молекулярной информатики как синтеза физико-химии полимеров и информационных технологий // Известия научнотехнического общества «КАХАК». - 2018. - №1 (60). - С. 60-75.

\section{Аликулов А.Ж., Серікбай А.М., Молдахан И. \\ Ғылыми жетекші: Мун Г.А.}

\section{Наноөлшемді құрылымдарға ақпаратты макроскопиялық жазу мәселелері}

Андатпа. Жұмыста екі кіріске ие, екі түрлі термодинамикалық айнымалыға жауап беретін нейрондарды қолдану тәсілі көрсетілген. Макромолекулалық жүйелер пысықталды, олар шын мәнінде нейрондық желінің аналогы болып табылады және молекулалық деңгейде ақпаратты жазуға мүмкіндік береді.

Кілт сөздер: инфокоммуникациялық технологиялар, нейрондық желілер, нанотехнологиялар, макромолекулалық жүйелер.

\section{A.Zh. Alikulov, A.M. Serikbay, I. Moldakhan Scientific superviser: Mun G.A.}

\section{Problems of macroscopic recording of information in nanoscale structures}

Abstract. The paper shows an approach using neurons with two inputs that respond to two different thermodynamic variables. We have developed macromolecular systems that are really analogous to a neural network and that allow us to record information at the molecular level.

Keywords: information and communication technologies, neural networks, nanotechnology, macromolecular system.

\section{Сведения об авторах:}

Мун Григорий Алексеевич, д.х.н., профессор, зав. кафедры «Химии и технологии органических веществ, природных соединений и полимеров» Казахского национального университета им. аль-Фараби.

Аликулов Адилет Женисбекулы, докторант второго курса Казахского Национального университета им. аль-Фараби.

Серікбай Абылайхан Мұратұлы, докторант первого курса Казахского Национального университета им. аль-Фараби.

Молдахан Инабат, докторант 2 курса Алматинского университета энергетики и связи им. Г. Даукеева.

УДК 004.735

Азберген К.Т.

Международный университет информационных технологий

Алматы, Казахстан

Научный руководитель: Айтмагамбетов А.3.

\section{КОГНИТИВНОСТЬ СВЕРХШИРОКОПОЛОСНЫХ РАДИОСИСТЕМ}

Аннотация. В статье рассмотрены методы, позволяющче достичь высокой степени адаптации сверхширокополосных систем к изменяющимся условиям передачи. Приведены основные требования, предъявляемые к системам когнитивного радио, применение подобных систем и их характеристики.

Ключевые слова: когнитивное радио, свехиирокополосные системы, когнитивность.

International Journal of Information and Communication Technologies, Vol.1, Issue 1, March, 2020 


\section{Введение}

Сверхширокополосные радиосистемы можно отнести к когнитивным системам, использующим модель иерархического доступа для динамического управления спектром. Так как, высокая скрытность, универсальность и простота реализации сверхширокополосных систем делают их потенциальными кандидатами для применения в сетях когнитивного радио.

Задача синтеза импульса специальной формы возникла из задачи обеспечения электромагнитной совместимости сверхширокополосных и узкополосных сигналов исходя из заданных норм на излучение. По заданной маске спектра производится синтез импульса с параметрами, удовлетворяющими заданным нормам на излучение.

\section{Методы, обеспечивающие когнитивность сверхширокополосных систем}

Несмотря на то, что изначально считалось, что сверхширокополосные сигналы не создают помех в заданном частотном диапазоне, так как работают ниже уровня шумов, все же высказывались опасения об их негативном влиянии на системы навигации, радиоастрономии и другие системы, где помехи даже с малым уровнем нежелательны. Очевидно, что широко применяемый в первых сверхширокополосных системах гауссовский моноцикл не всегда хорошо вписывался в маску спектра. Тогда было предложено максимально подавлять или даже вырезать те участки спектра сверхширокополосного сигнала, где работают данные системы. Для преодоления вышеназванной проблемы было найдено несколько решений, которые впоследствии были развиты в сторону адаптации спектрального состава импульса к меняющейся помеховой обстановке [5].

К примеру, импульс в виде гауссовского моноцикла можно предварительно отфильтровать с помощью цифрового фильтра с конечной импульсной характеристикой. Пример спектра синтезированного импульса приведён на рис. 1. Преимуществом данного метода можно считать также то, что с помощью него можно синтезировать ортогональные импульсы, обладающие хорошими авто- и взаимокорреляционными свойствами.

Адаптивный метод формирования импульса основан на итеративном алгоритме, в котором используется линейная комбинация производных гауссовского импульса. Алгоритм выполняется до тех пор, пока не будет найдена удовлетворительная аппроксимация заданной спектральной плотности мощности.

Еще одним методом формирования сверхширокополосного импульса являются методы, основанные на применении негауссовой формы импульса, а именно модифицированных эрмитовых импульсов, модифицированных импульсов формы «приподнятый косинус», ортогональных полиномиальных импульсов. Известны алгоритмы, основанные на применении нейросетевых методов, вейвлет-функций и вейвлет-преобразований.

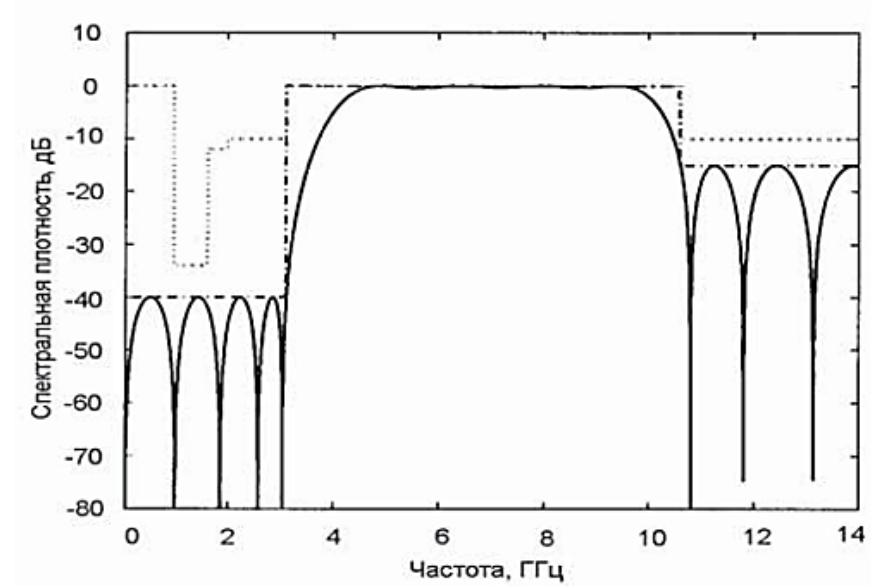

Рисунок 1 - Спектр импульса, синтезированного с помощъью последовательного алгоритма

International Journal of Information and Communication Technologies, Vol.1, Issue 1, March, 2020 
Среди разнообразных форм импульсов следует отметить применение импульсов с линейной частотной модуляцией, позволяющих получить наиболее равномерный спектр в заданной полосе частот. Предложено было формировать передаваемый импульс с помощью линейной комбинации гармонических импульсов с гауссовской огибающей (1):

$$
s(t)=\sum_{k=1}^{k} A_{k} \exp \left(j 2 \pi f_{k} t+\varphi_{k}\right) \exp \left(\alpha_{k} t^{2} \pi / 2\right)
$$

Основные выводы, которые были сделаны в результате этих исследований:

- более жесткие требования к форме спектра приводят к длительному появлению хвостов импульса;

- очень важна синхронность суммирования - абсолютная нестабильность даже одного генератора, равная 0.05 и выше приводит к значительному изменению формы импульса и желаемого спектра;

- в результате получаемый импульс суммирования имеет высокий пик-фактор.

Несмотря на разнообразие методов и активность исследований в этой области следует отметить еще один существенный недостаток, возникающий при применении методов синтеза формы импульсов - все они не учитывают последствия прохождения синтезированных импульсов через антенный тракт и среду передачи. При этом возможны такие искажения, которые сведут на нет все преимущества адаптации формы импульса. Поэтому следующим шагом в разработке когнитивных сверхширокополосных систем явилось создание антенн с реконфигурируемыми полосами подавления [6]. Применение таких антенн возможно в обоих режимах: и на вторичной основе и в режиме перемежения, однако во втором режиме работа такой антенны является более устойчивой.

\section{Перспективы использования когнитивных сверхширокополосных радиосистем}

В заключение следует ответить на главный вопрос - в чем состоит выигрыш при применении подобных систем, точнее, каковы их характеристики. Проведенный анализ работ в этой области показал, что эффективность работы когнитивных радиосистем, в том числе сверхширокополосных, принято оценивать с помощью зависимости максимальной спектральной эффективности от отношения сигнал-шум или от вероятности ошибки на бит. Предлагается также оценивать абсолютный прирост спектральной эффективности при использовании сверхширокополосными системами уже занятых частотных полос [7].

Важной характеристикой также является время зондирования спектра и размер окна временной интервал, в течение которого производится зондирование спектра. В ряде работ используется традиционная оценка энергетической эффективности таких систем с помощью зависимости вероятности ошибки от отношения сигнал-шум. В таблице 1 приведены результаты сравнения сверхширокополосных систем когнитивного радио, использующих различные технологии (методы модуляции, способы передачи, частотный диапазон).

Несмотря на указанные преимущества сверхширокополосных систем в качестве элементов когнитивного радио, существует ряд проблем, возникающих при их применении и требующих исследования и разработки:

- влияние интерференции первичных пользователей на сверхширокополосной системе;

• интерференция «когнитивных пользователей»;

- многопользовательская внутрисистемная интерференция;

- увеличение скорости адаптации к изменяющимся условиям.

International Journal of Information and Communication Technologies, Vol.1, Issue 1, March, 2020 
Таблица 1 - Характеристики сверхширокополосных систем

\begin{tabular}{|l|l|l|l|l|}
\hline Метод модуляции, технология & $\begin{array}{l}\text { Дальность } \\
\text { действия, м }\end{array}$ & $\begin{array}{l}\text { Скорость } \\
\text { передачи, } \\
\text { Мбит/с }\end{array}$ & $\begin{array}{l}\text { Диапазон } \\
\text { частот, ГГц }\end{array}$ & $\begin{array}{l}\text { Спектральная } \\
\text { эффективность, } \\
\text { бит/с/Гц }\end{array}$ \\
\hline 2-АИМ импульсная & 100 & 1 & $3.1-10.6$ & 0.1 \\
\hline $\begin{array}{l}\text { M-QAM } \\
\text { MB-OFDM многочастотная }\end{array}$ & $1-10$ & $54-480$ & $3.1-10.6$ & до 1 \\
\hline $\begin{array}{l}\text { M-QAM } \\
\text { MB-OFDM многочастотная }\end{array}$ & 10 & 1000 & $57-64$ & 1 \\
\hline 4-FSK & $1-1000$ & $10-1000$ & $3.1-10.6$ & $0.1-10$ \\
\hline
\end{tabular}

Таким образом особенности сверхширокополосных технологий удовлетворяют основным требованиям, предъявляемым к системам когнитивного радио. К ним относятся: незначительная интерференция, возможность динамического управления спектром, возможности мониторинга спектра, множественного доступа и безопасности. Для уменьшения влияния помех от сверхширокополосных систем, используемых а когнитивном радио, применяются два основных метода: формирование специальной формы импульса и конструирование антенны. Указанные системы позволяют достичь увеличения общей спектральной эффективности при совместном использовании спектра частот.

\section{ЛИТЕРАТУРА}

1. Рекомендация МСЭ-P SM.2152 (2009) «Программно определяемое радио (SDR) и Когнитивные радио системы (CRS)»

2. Митола Дж. Cognitive Radio - интегрированная агентская архитектура для ПО. Когнитивное Радио. //Королевский технологический институт, Швеция - 2002. - C. 32-45.

3. Рабочие материалы координатора по пункту 1.19 повестки дня ВКР-11. - РСС, Документ РГ2011/12-РГ2, 14 октября 2008 г, Приложение 1.19.

4. Володина Е.Е., Девяткин Е.Е. Экономические аспекты управления использованием радиочастотного спектра. - // Брис-М, 2011. - С. 196.

5. Фролов А.А. Применение сверхширокополосных систем для решения проблемы дефицита РЧС // Вестник связи. -2012. - № 9. - С. 12-16.

6. Косичкина Т.П., Сидорова Т.В., Сперанский В.С. Сверхширокополосные системы телекоммуникаций. - // Инсвязь-издат, 2008. - С. 408-511.

7. Сперанский В.С., Спирин А.П., Фролов А.А., Косичкина Т.П. Перспективы развития сверхширокополосных систем связи в направлении когнитивного радио // СИНХРОИНФО, 2015. - С. 9-11.

\section{Азберген К.Т.}

Ғылыми жетекші: Айтмагамбетов А.3.

\section{Ультра кен жолақты радио жүйелердің танымдылығы}

Андатпа. Мақалада ультражолақты жүйелерді берілудің өзгеретін жағдайларына бейімделудің жоғары деңгейіне қол жеткізу әдістері қарастырылған. Танымдық радио 
жүйелерге қойылатын негізгі талаптар, мұндай жүйелерді пайдалану және олардың сипаттамалары келтірілген.

Түйінді сөздер: танымдық радио, кең жолақты жүйелер, танымдылық.

\title{
Azbergen K.T.
}

Scientific superviser: Aitmagambetov A.Z.

Cognitiveness of ultra-wideband radio systems

Abstract. The article discusses methods to achieve a high degree of adaptation of ultrawideband systems to changing transmission conditions. The basic requirements for cognitive radio systems, the use of such systems and their characteristics are given.

Key words: cognitive radio, super wideband systems, cognitiveness.

\section{Сведения об авторах:}

Азберген Қарлығаш Тастанбайқызы, магистрант кафедры «Компьютерной инженерии и информационной безопасности» Международного университета информационных технологий.

Айтмагамбетов Алтай Зуфарович, профессор кафедры «Радиотехника, электроника и телекоммуникации» Международного университета информационных технологий.

УДК 004.03

\author{
Даирбаева C.A. \\ Международный университет информационных технологий \\ Алматы, Казахстан \\ Научные руководители: Синчев Б.К., Рысбайулы Б.

\section{ОПРЕДЕЛЕНИЕ ФУНКЦИОНАЛЬНЫХ ТРЕБОВАНИЙ К ИНФОРМАЦИОННОЙ СИСТЕМЕ МАГИСТРАЛЬНОГО ТРУБОПРОВОДА}

Аннотация. В статье рассмотрены функииональные требования к информационной системе магистрального трубопровода. Объектом исследования выбран нефтепровод Узень-АтырауСамара. В качестве примера разработан информачионный блок карты нефтепровода. Приведены основные требования к разрабатываемой системе, информационному обеспечению, безопасности и разграничению доступа, графическому дизайну.

Ключевые слова: информационная система, магистральный трубопровод, блок карть нефтепровода.

\section{Введение}

Появление новых технологий и повсеместное увеличение добычи нефти способствовало повышению уровня автоматизации технологических процессов в нефтяной отрасли и созданию принципиально новых информационно-управляющих систем, главная цель которых - обеспечение бесперебойной, надежной и эффективной работы магистрального нефтепровода [1].

Для расширения возможностей информационно-управляющих систем необходима разработка автоматизированного вычислительного комплекса, позволяющего контролировать изменения тепловых процессов и технологических параметров нефтепровода. Такие системы используют новейшие технологии, средства и математические методы с целью освобождения человека от участия в процессах получения, преобразования, передачи

International Journal of Information and Communication Technologies, Vol.1, Issue 1, March, 2020 